\title{
How to Deal with the Upcoming Challenges in GMO Detection in Food and Feed
}

\author{
Sylvia R. M. Broeders, Sigrid C. J. De Keersmaecker, and Nancy H. C. Roosens \\ Platform Biotechnology and Molecular Biology, Wetenschappelijk Instituut Volksgezondheid-Institut Scientifique de Santé Publique \\ (WIV-ISP), J. Wytsmanstraat 14, 1050 Brussel, Belgium
}

Correspondence should be addressed to Nancy H. C. Roosens, nancy.roosens@wiv-isp.be

Received 30 March 2012; Accepted 13 September 2012

Academic Editor: Joel W. Ochieng

Copyright ( 2012 Sylvia R. M. Broeders et al. This is an open access article distributed under the Creative Commons Attribution License, which permits unrestricted use, distribution, and reproduction in any medium, provided the original work is properly cited.

\begin{abstract}
Biotech crops are the fastest adopted crop technology in the history of modern agriculture. The commercialisation of GMO is in many countries strictly regulated laying down the need for traceability and labelling. To comply with these legislations, detection methods are needed. To date, GM events have been developed by the introduction of a transgenic insert (i.e., promoter, coding sequence, terminator) into the plant genome and real-time PCR is the detection method of choice. However, new types of genetic elements will be used to construct new GMO and new crops will be transformed. Additionally, the presence of unauthorised GMO in food and feed samples might increase in the near future. To enable enforcement laboratories to continue detecting all GM events and to obtain an idea of the possible presence of unauthorised GMO in a food and feed sample, an intensive screening will become necessary. A pragmatic, cost-effective, and time-saving approach is presented here together with an overview of the evolution of the GMO and the upcoming needs.
\end{abstract}

\section{Introduction}

Commercialisation of biotech or genetically modified (GM) crops was started in 1996. Since this date a 94 -fold increase (from 1.7 million hectares in 1996 to 160 million hectares in 2011) was observed, which makes biotech crops the fastest adopted crop technology in the history of modern agriculture [1]. In 2011, 29 countries were planting biotech crops of which 19 developing countries and 10 industrial ones [1]. Between the developing countries, Brazil is the leader $[1,2]$ with 30.3 million hectares and an increase of $20 \%$ was seen compared to 2010. The other main countries are Argentina (23.7 million ha), India (10.6 million ha cotton), China (3.9 million ha), and South Africa (2.3 million ha). The United States of America are still the lead producer of biotech crops amongst the industrial countries with 69 million hectares of biotech crops and an increase of 5\% in the last year.

Since 1996, sixty countries worldwide have granted regulatory approvals for biotech crops for import for food and feed use and for release into the environment, corresponding to a total of 1045 approvals for 196 GM events in 25 crops.
USA still tops the list of number of approved GM events followed by Japan, Canada, Mexico, South Korea, Australia, the Philippines, New Zealand, the European Union, and Taiwan [1]. In many countries legislations concerning GMO commercialisation have been adopted and although they differ from country to country, some issues are common. The assessment of new GMO, for example, is in any state done on a case-by-case basis. Further, a distinction is always made between the purpose of the GMO namely if it is intended for contained use or for release into the environment. In addition, the countries make also a division between growing of GMO or using it in the food and feed chain (e.g., as raw or processed material). Concerning the labelling threshold for food and feed, however, there is no consistency as this is only in place in some but not all countries and it may vary from $0.9 \%$ in the EU [3] to $5 \%$ in Japan [4]. In some countries like Russia, on the other hand, the labelling is dependent on the type of product. Food products such as oil, syrups, and starch, do not require labelling [5].

The various regulations worldwide governing the authorisation of GMO lead to the fact that some GMO approved 
in an exporting country may enter involuntarily via feed and food importation in another country where the status of approval of the GMO is not the same (i.e., unauthorised GMO or UGM). The accidental presence of such kind of UGM will increase in the coming years. Indeed, until now, the GMO in food and feed currently commercialised have been developed by American and European biotech companies. These developers have a major interest in requesting authorisation for the introduction of their GM event on the world market as their products are meant for exportation. However, in 2015 more than half of the GMO will be developed by research institutions $[2,6]$. This trend has already started worldwide. In Asia, for example, the International Rice Research institute (IRRI) in the Philippines has successfully bred different GM varieties which are moving forward in the regulatory pipelines for the Philippines and Bangladesh [1]. In Brazil, a genetically modified Phaseolus bean, resistant to the golden mosaic virus was developed by the Brazilian public Agricultural Research Corporation (Embrapa) and has been approved for commercial release by the National Technical Commission on Biosafety (CTNBio) [7]. Further, projects concerning the improvement of the level of micronutrients in banana are being led by the Queensland University of Technology (Australia) in partnership with the National Agricultural Research Organisation of Uganda (see http://www.grandchallenges.org/). As these GMO are mainly intended for local consumption or limited export [6] no worldwide application for authorisation will be filed and therefore these GMO will be considered as unauthorised as soon as they appear outside these markets. As such, the various sources of GMO producers will increase the risk of the presence of UGM in food and feed samples.

Furthermore, escapes from field trial releases are another source of UGM that can represent a significant risk to health and the environment. In recent years, a number of such cases of accidental releases have been observed. For example, soybean and sorghum fields planted on former GM maize test plots have been found to be contaminated with a GM maize developed by the US biopharmaceutical company ProdiGene to produce an experimental pig vaccine $[8,9]$. Zapiola and coworkers [10] also showed evidence for transgene flow of glyphosate resistant creeping bent-grass (Agrostis stolonifera L.; a golf grass) from the field trials not only during the time the plants were setting seeds but also after the fields were taken out of production. Also the finding of traces of genetically modified Liberty Link 601 rice in US exports shows the difficulties of full containment of field trials [11]. It is expected that the number of GMO planting countries will increase in the coming years and that consequently the number of regulatory approvals will follow the same trend. In addition, new crops and new traits will be commercialised.

In this paper, we will briefly summarise the currently used detection methods in food and feed samples. Subsequently, we will elaborate on the envisaged evolution of the GMO crops and the challenge for the detection methods this will create. It is clear that the increase in the number and diversity of GMO and the growing possibility of the presence of UGM will necessitate a reevaluation of the one-by-one approach presently used in GMO detection/identification as this will become practically impossible and too costly. Consequently, there is an urgent need for efficient strategies for the detection of all these GMO both to comply with the unique regulation of each country but also to limit the potential health and environmental risks associated with UGM.

\section{Currently Used Methods for GMO Detection}

Most of the current plant GM events are created by inserting a transgenic DNA construct into the host genome. The resulting organism will exhibit new properties due to the fact that the foreign DNA sequence encodes a new protein expressed in this plant. From these characteristics, basically, two types of methods were developed to detect GMO, namely, protein- and DNA-based methods ([12-15] and references therein). Protein-based methods have some drawbacks as previously discussed $[13,16]$. In addition, this type of methods has another limitation based on the fact that they target the product resulting from the genetic modification and not directly the genetic modification that is at the origin of the GMO which is the fundamental advantage of DNAbased methods (see below). Consequently, the methodology only allows identifying the presence of the transgenic protein but does not permit to differentiate between different events containing the same transgenic construct. They do thus not allow an unequivocal identification of the GMO, which can be a problem to ensure traceability. Furthermore, some proteins are instable and most of them are nearly impossible to be reliably detected in processed products. Therefore, the following part focuses on DNA-based detection methods.

Several review publications are available concerning DNA-based methods [12, 17-22]. In addition, the compendium established by the Joint Research Centre (JRC) focuses as well on DNA-based reference methods for GMO analysis [23].

At present, the most commonly used DNA-based methods are based on the amplification of a specific DNA fragment (i.e., element and construct-specific methods) or the unique junction between the transgenic insert and the host genome (i.e., event-specific methods) using the Polymerase Chain Reaction (PCR) technology (http://users.ugent.be/ avierstr/principles/pcr.html). The method relies on subsequent cycles of repeated heating and cooling of the DNA strands and enzymatic replication of the DNA. The basic technique of detection using PCR is the use of a heat stable enzyme (Taq polymerase) allowing the exponential amplification of the DNA followed by the migration of the amplified DNA fragment(s) by agarose gel electrophoresis. This technique allows estimating the size of the DNA fragment(s). At the present time, a more advanced quantitative real-time PCR technology exists and enables to determine the content of a GMO in a sample. The amount of product synthesised during the PCR is measured in real time by the detection of a fluorescent signal. The most common chemistries used to produce the fluorescent signal are the use of a specific fluorescent probe (Taqman) or using dsDNA binding (intercalating) fluorescent dyes (e.g., SYBR Green I). 
By recording the amount of fluorescence emission at each cycle, it is possible to monitor the reaction during its exponential phase and subsequently to correlate the fluorescent signal with the initial amount of target template. Beside these two main real-time PCR chemistries, others have been applied for the detection of GMO [24-26] but will not be further discussed.

In SYBR Green chemistry [27], the fluorescent dye SYBR Green I, which binds to the minor groove of dsDNA, is used. This dye will bind to every dsDNA, including nonspecific PCR products and primer dimers. This is the major limitation of this system. To circumvent this problem, a melting curve analysis can be performed at the end of the PCR, that is, measuring the DNA dissociation in function of the temperature. Each dsDNA has a specific melting temperature as a direct property of its nucleotide content. Based on this melting temperature, it is possible to distinguish the nonspecific fragments from the specific PCR products. This analysis allows us to detect not only the specific products but also to get an idea on the presence of closely related targets [28]. In addition, the SYBR Green chemistry is cost saving as there is no need for the use of a fluorescent-labelled probe, which is the case with the TaqMan chemistry.

Indeed, the TaqMan chemistry [27] uses three specific oligonucleotides, that is, two primers and a probe [29-31]. The probe is labelled at its $5^{\prime}$-end with a "reporter" fluorescent dye and at its $3^{\prime}$-end with a "quencher". As long as the two dyes are in each other's vicinity, the quencher prevents the emission of fluorescence of the reporter. During the elongation phase of the real-time PCR, the Taq polymerase cleaves the annealed probe $\left(5^{\prime} \rightarrow 3^{\prime}\right.$ exonuclease activity). The fluorescence from the freely released reporter is detected and monitored. The fluorescence increases proportionally to the DNA quantity present in the reaction with each amplification cycle. This correlates with the increase in the copy number of the amplified target. The use of three oligonucleotides allows a more specific detection. However, at the same time it reduces the flexibility of the system as it will not allow detecting mutated sequences (e.g., caused by genetic variation of species varieties). In addition, TaqMan amplicons need to be longer as both primers and probe need to be designed in a conserved region. This is an additional drawback when working with processed samples in which the DNA might be degraded. Taqman real-time PCR is also a technology that allows multiplexing by using different fluorescent dyes for different targets to be simultaneously detected in one sample [32-34]. However, seeing the limitation of the number of fluorescent dyes that can be detected by the current real-time PCR instruments and the fact that multiplex PCR becomes more prone to false positives if more than five to 10 real-time PCR systems are to be combined [18], only a maximum of 5-6 targets is possible. One should further guarantee that the detection and quantification of the different targets in a single tube is not impaired, that is, the sensitivity and PCR efficiency should be equal as when the reactions are run in simplex. In addition, attention should be paid to the design of the different primers so that they cannot interact with each other, that is, primer dimer formation.
Apart from real-time PCR, new alternative and advanced technologies have been proposed including the use of high-throughput systems or platforms for the detection of multiple targets, for example, microarrays, MIPC, PCR combined with capillary gel electrophoresis (fingerprinting), and next generation sequencing $([12,18,35-38]$ and references therein). However, at the present stage they are often more expensive, difficult to standardise and validate, and require extensive, specialised work and equipment. They are still at the proof of concept stage and therefore not applicable in routine testing at the moment. Consequently, these methods will not be discussed as this paper focuses on upcoming challenges for GMO detection in food and feed by enforcement laboratories.

\section{Evolution of GMO}

The genetically modified plants that have been developed and commercialised so far, are mainly transformed using a transgenic insert. This cassette consists of a regulatory promoter region, a coding sequence (trait), and a terminator (scheme in Figure 1).

The promoter and terminator elements used in the first GMO were mostly the cauliflower mosaic virus (CaMV) $35 \mathrm{~S}$ promoter (p35S; [39]) and the Agrobacterium tumefaciens nopaline synthase terminator (tNOS; [40]). The traits were also limited to genes conferring herbicide tolerance (HT) and insect resistance (IR) and were introduced into few commodity crops such as maize, soybean, and oilseed rape. The main HT sequences are the bacterial phosphinotricin- $N$ acetyltransferases from Streptomyces viridochromogenes (pat) and from Streptomyces hygroscopicus (bar) [41] and the 5enolpyruvylshikimate-3-phosphate synthase (epsps) from the Agrobacterium tumefaciens strain CP4 or from plant origin (in casu petunia) [42, 43]. For the IR trait, artificial versions of the Bacillus thuringiensis (Bt) $\delta$-endotoxin encoding genes (e.g., the $c r y I A b / A c$ ) have been utilised.

At the present time, this first-generation of traits and regulatory elements remains prominent in commercial crops and their derived food and feed products. Indeed, in 2011, the main GM crop was still soybean with $47 \%$ of the global biotech crop area followed by maize (32\%), cotton (15\%), and oilseed rape (5\%). Throughout the 16 years of biotech crop commercialisation, herbicide tolerance has been the dominant trait (59\%). Insect resistant crops account for 15\% of the total area of planted transgenic crops [1].

In more recent years, new regulatory sequences have been introduced $[44,45]$ such as the cauliflower mosaic virus $35 \mathrm{~S}$ terminator ( $\mathrm{t} 35 \mathrm{~S}$ ), the figworth mosaic virus promoter (pFMV; [46]), the Agrobacterium tumefaciens nopaline synthase promoter ( $\mathrm{pNOS}$ ), the rice actin promoter (pAct; [47]), and the maize ubiquitine promoter (pUbiZM; [48]). Furthermore, new genes from the Bt $\delta$-endotoxin family are also being used now $(c r y 3 B b, \operatorname{cr} y 3 A, c r y 1 F, \ldots)$. Moreover, more species like rice, cotton, sugarbeet, and potato are currently used for transformation.

In the coming years, an even larger panel of genes encoding various traits and new plant species are being genetically 


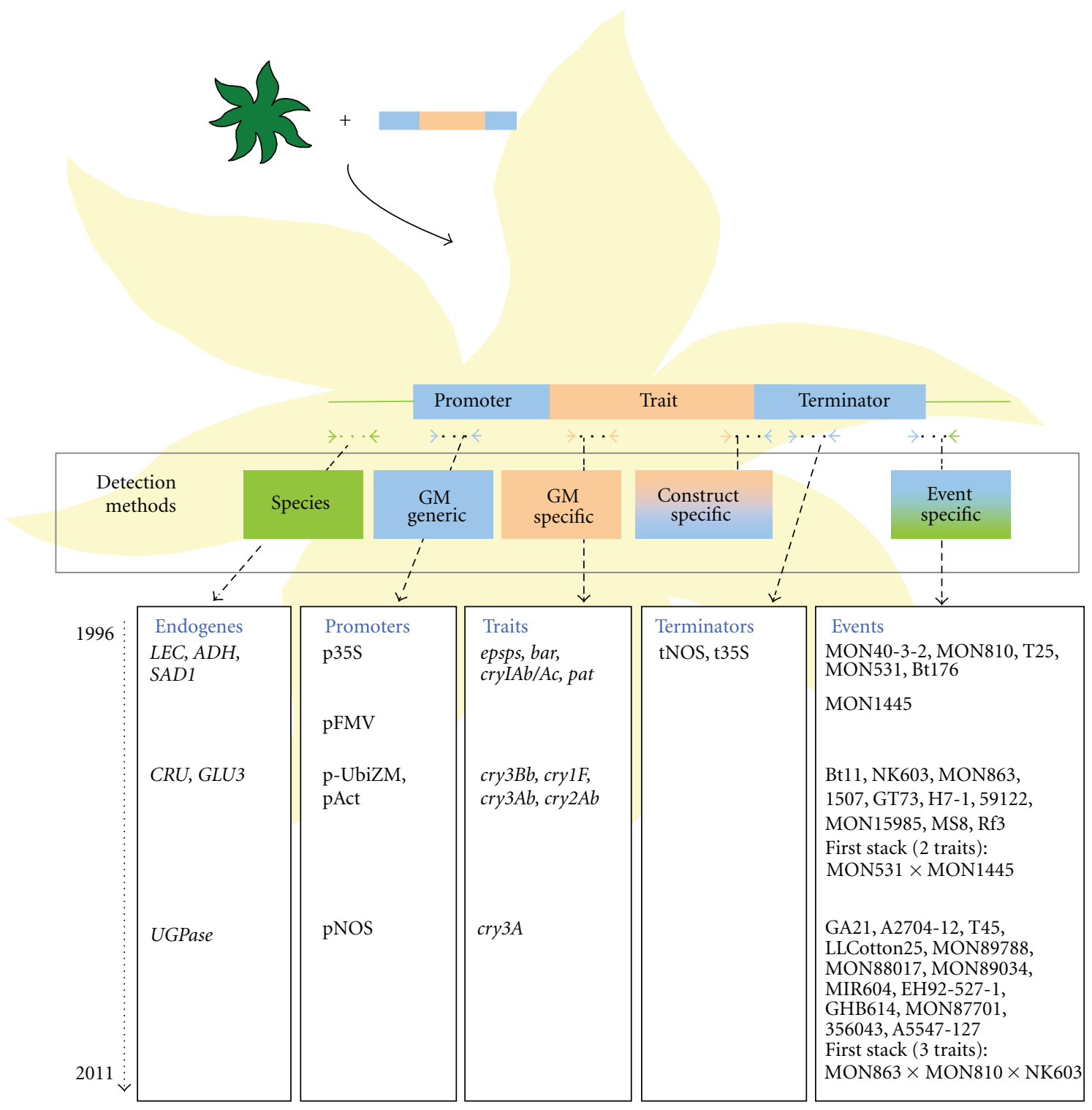

FIGURE 1: Evolution of the currently GM events authorised in the EU and their respective markers. This list is voluntarily not exhaustive but aims at giving the general trend in GMO evolution (see text and JRC Compendium [23] for details).

modified and brought onto the feed and food market. The diversity of transgenes and species used can be illustrated by the following examples. Hawaiian researchers have developed a papaya (Carica papaya) resistant to the papaya ringspot virus [49] which was commercialised in 1998 and is being exported to Canada since 2003. They further collaborated with other countries such as Brazil, Jamaica, and Thailand to develop resistant transgenic papaya suitable for these countries $[50,51]$. Also eggplant (Solanum melongena L.) for instance, has been modified to confer resistance to the Colorado potato beetle (Leptinotarsa decemlineata Say; [52]) by the expression of Bt genes. Cassava (Manihot esculenta Crantz), on the other hand has been modified to reduce the amylase content in the starch [53] which is important for industrial purposes such as paper and textile [54].
In addition to these single trait GMO, a new trend of gene stacking has been observed [55]. This implies the introduction of different transgenic inserts into the same plant through conventional crossbreeding, co-, or retransformation to combine different traits $[55,56]$. This trend is confirmed by the considerable boost in 2011 of planting of stacked events with an increase of $31 \%$ compared to the year before. In 2011, 12 countries have been growing events with two or more traits. The total area of stacked events accounts for more than $26 \%$ of the 160 million hectares of biotech crops planted $[1,2,6]$. In this context, rice (Oryza sativa), a predominant food source in Asian countries, has been genetically modified by the insertion of two genes (encoding phytoene synthase and carotene desaturase) to improve the production and accumulation of $\beta$-carotene in the grains 
$[57,58]$. This GMO is in the pipeline for regulatory approval in the Philippines and Bangladesh [1]. An extremely evolved form of gene stacking is the SmartStax GMO. It is the first plant GMO with eight combined events for multiple modes of insect resistance and herbicide tolerance. The SmartStax is a combination of Yieldgard VT Triple (Monsanto), Herculex Xtra (Dow), RoundUp Ready 2 (Monsanto), and Liberty Link (Dow). It is currently available for maize, but cotton, soybean, and speciality crop variations are to be released [59].

In the above described GMO, the introduced genetic elements are mainly coming from a noncrossable organism (so-called donor organism). These elements are further combined with plant-specific markers such as the rice actin promoter and the maize ubiquitin promoter to construct the transgenic insert. However, other types of modifications in the genome can be introduced to alter the plant's characteristics. Several of these techniques have already been adopted by commercial plant breeders (especially in the USA). One of these is the introduction of a DNA sequence which is completely derived from the recipient species itself in a process that is called cisgenesis [60]. This technique together with oligonucleotide directed mutagenesis (ODM) and agroinfiltration are the most used new breeding techniques [60]. Zinc finger nuclease (ZFN) technology, RNA-dependent DNA methylation (RdDM), grafting on GM rootstocks, and reverse breeding are less used. They are still mainly applied at research level. It should however be noted that discussions are still ongoing whether the organisms created by these plant breeding methods will fall under the current GMO regulation or not.

\section{Evolution of the Screening Strategy in Response to the GMO Complexity}

Due to the broad range of GMO, authorised and unauthorised, possibly present on the worldwide and local market, it rapidly becomes unrealistic to use a one-by-one based identification strategy. This step is necessary and an important task of the enforcement laboratories to unequivocally identify each GMO, that is, by targeting the DNA fragment on the junction between the plant genome and the transgene (event-specific method; [61]). Already now, strategies like simplex or multiplex real-time PCR (limited to 5-6 targets when using the real-time PCR technology) for the identification of known junction sequences (i.e., GM authorised events) are not rational as it is extremely expensive and time consuming. In the near future this will become simply impossible. Moreover, no event-specific methods are available for the UGM, especially the unexpected ones coming from field trials, and so they are undetectable with such kind of methodology. Therefore, most of the enforcement laboratories have elaborated a screening strategy, in which a minimum set of PCR tests (targeting specific genetic elements) should allow making conclusions on the absence/presence of as many GM events as possible. Only in the positive cases, a second step will specifically identify which individual event(s) is (are) present in the sample.
The most common recombinant elements in the current GM crops are $\mathrm{p} 35 \mathrm{~S}$ and tNOS [44, 45, 62], both transcription regulating sequences. Consequently, in order to assess the presence of GM material in a product, a screening PCR for those generic recombinant markers is often performed. Several methods have already been published for the detection of the p35S and tNOS markers in a broad range of matrices using classical PCR as well as more advanced real-time PCR with a TaqMan probe or the SYBR Green dye [28, 63-67]. This basic screening was very efficient when only few GMO were present on the food and feed market. However, as the number of GM events is growing exponentially, limiting the screening to those common targets (with high-coverage power) has the disadvantage that a too large number of GM needs to be confirmed using the event-specific detection methods. Therefore, additional targets (GM-specific elements) such as HR genes (pat, bar, epsps) and IR genes (cry gene family) can be added to reduce the number of putative GM events to be identified in the sample (due to a higher discriminative power). Several detection methods have been published targeting such types of elements [68-70].

The majority of the PCR methods described above were designed by different groups and consequently are using different methodologies (classical PCR, real-time PCR using the TaqMan, or SYBR Green chemistry) as well as different PCR programmes and protocols (e.g., [23]). This makes the simultaneous use in a single run in a 96-well plate format impossible by enforcement laboratories. To reduce the number of analyses and facilitate high-throughput analysis some multiplex real-time PCR screening strategies have been developed. However, these require multichannel detection devices and often include costly detection probes for at least some of the targets [32-34]. Furthermore, the multiplex strategy misses the flexibility of a modular system, that is, each time a new method needs to be added, the complete system needs to be validated.

In addition to this multiplex approach, a new type of modular screening strategy can be used, that is, the socalled "combinatory" or "matrix-approach". In this screening approach, a limited set of simplex real-time PCR methods targeting various types of elements (endogenous sequences, generic markers, and GM-specific elements) is selected in such a way that multiple GMO can be detected within a single analytical run. Such a matrix-based approach was developed by the WIV-ISP [71, 72] and is used in routine GMO detection. A careful selection of the markers was performed allowing developing an approach wherein not only most GMO are detected but also discriminated $[28,68,72,73]$. Special attention was given to the size of the amplicon, that is, the methods were developed to amplify a short amplicon (around $100 \mathrm{bp}$ ) that is particularly important to detect transgenes in processed food where the DNA might be degraded. Combined with an informatic decision support tool named CoSYPS (for "Combinatory SYBR Green qPCR Screening"), such GMO screening represents an example of a very useful approach in managing the experimental analysis of samples for regulatory or enforcement purposes and is further elaborated below. 
The CoSYPS for GMO detection was first designed to be able to combine the results obtained with 11 SYBR Green real-time PCR methods which were in-house developed to be performed under similar conditions and hence to be run in a single 96-well plate (Table 1). Hereto, two generic recombinant markers (p35S, tNOS) and the 4 major GM elements (cryIAb/Ac, epsps, pat, and bar) have been designed. Many of the elements used in transgenic constructs are derived from donor organisms such as bacteria and viruses. One such element is the $35 \mathrm{~S}$ promoter of the cauliflower mosaic virus (CaMV) which has Brassica plants as its natural host. To discriminate between the p35S present in a GM event and the one due to its possible natural presence, an additional marker (CRT) was developed. This marker targets the reverse transcriptase gene of CaMV and will thus allow the detection of the virus. These GM markers are combined with the RBCL plant kingdom marker and a lectin (LEC), an alcohol dehydrogenase $(A D H)$, and a cruciferine $(C R U)$ species marker for the detection of materials derived from soybean, maize, and oilseed rape, respectively. As this approach is modular, three additional markers were developed to answer the actual need in GMO detection. Two are targeting the promoters of the figworth mosaic virus (pFMV) and the A. tumefaciens nopaline synthase (pNOS), one targets the $\delta$-endotoxin encoding gene $c r y 3 B b$ from $B$. thuringiensis. To keep covering the newly developed GMO, three more species-specific methods have been developed, that is, targeting rice $(P L D)$, cotton (SAD1), and sugarbeet (GLU3). Based on the decision values (LOD expressed as $\mathrm{Ct}$ value, $\mathrm{Tm}$ ) of the different screening methods, the CoSYPS allows to decide which GM events may be present in an analytical sample. The present version of the CoSYPS allows covering the presence of all currently EU authorised GMO [28, 68, 72, 73]. An example of the efficient use of this decision support system is shown in Figure 2 for the detection of maize event NK603.

As this decision support system is a modular tool, screening methods targeting new sequences present in new GM events can be added at any moment. This is necessary to add discriminative power to the CoSYPS system and to keep covering the increasing number of GMO. Additionally, the use of the various markers in combination with the CoSYPS is a powerful tool in the detection of UGM. Indeed, in principle, the elements that are positive in the screening real-time PCR should be covered by the EU authorised events [77] or the GM events included in the "Low Level Presence" (LLP) legislation [78]. If this is not the case, one might suspect the presence of an UGM in the sample and further confirmation of the event would be needed. This might require first the use of alternative and advanced tools such as anchor-PCR fingerprinting [79] followed by confirmatory sequencing of the suspected amplified fragment(s) or DNA walking [80] to identify the junction between the transgene and the plant genome (for which later on a real-time PCR event-specific method can be developed). Alternatively, the next generation sequencing technology can be used to screen whole genomes for foreign DNA and their respective junctions. The roadmap for these ad hoc scenarios should be drawn based upon the evaluation of the perceived risk for health, environment, and economy.

\section{Conclusions and Future Perspectives}

The number of GMO cultivated for commercial or research purposes continues to increase worldwide. Not only these will add to the complexity of detecting authorised GMO by the enforcement laboratories in food and feed samples, but also the occurrence of UGM which will be steadily increasing in the coming years. Unintended escapes and intermingling with UGM can never be ruled out [81]. Most likely there will also be a growing number of GMO with traits of industrial or pharmaceutical relevance but not intended for food or feed use. These could also enter the agricultural supply chains and cause ethical and religious concern or even pose a significant risk to human and animal health [38]. Therefore, there is an evident need for a continuous development of appropriate detection methods and strategies.

As long as the development of GMO is following the same way and genetic modifications are being created by the introduction of a transgenic cassette originating from a foreign organism, the current detection/identification approaches can be continued to be used, even for stacked events. However, gene stacking poses a new challenge for GMO detection laboratories as there is no way (except when the analysis is done on individual seeds and plants) to discriminate between the presence of the GMO separately in a sample or combined as a stacked event $[16,55,82]$.

In response to the increasing diversity of GMO on the market, new screening markers for the new species-specific sequences (e.g., eggplant and melon), and new genetic elements (e.g., coding for pathogen resistance) will need to be designed and developed. The challenge will be more in collecting the massive amount of data sequences (especially for UGM) to develop standardised real-time PCR methods and then combining the obtained results in an appropriate decision system, like CoSYPS, for an efficient manner of GMO testing. Eventually, also the event-specific methods should be developed, to unambiguously identify the GMO in a second step.

The developed SYBR Green screening methods will offer the possibility for the detection of potential allelic variation in GM markers, as is, for example, the case for the cry $1 \mathrm{Ab}$ gene in Bt11, Bt176, and MON810 maize, as compared to the natural (non-GM) donor Bt ssp. kurstaki. The haplotypes of the gene in the three GM maize events have been differently optimised for expression in plants/maize [38]. The SNP can however be detected by using a technique originating from human genetic diagnostics, that is, High Resolution DNA Melting Analysis (HRM) to screen for mutations in DNA pools [83]. This requires only a simple real-time PCR step (using an intercalating saturating dye such as SYTO9 or LCgreen Plus+ and the primers developed for the screening markers) followed by DNA melting curve analysis. Samples containing a mutation form heteroduplexes in the post-PCR fragment mix. These are identified as differential melting temperature curves in comparison to homoduplexes (e.g., [84]). As such, HRM is a cost-effective, high-throughput 
TABLE 1: List of SYBR Green screening methods developed and validated at WIV-ISP.

\begin{tabular}{|c|c|c|c|}
\hline Method name & Target & $\begin{array}{l}\text { Fragment } \\
\text { size (bp) }\end{array}$ & Reference \\
\hline \multirow{2}{*}{ RBCL } & Ribulose-1,5-biphosphate carboxylase oxygenase & 95 & {$[73]$} \\
\hline & \multicolumn{3}{|l|}{ Plant taxon-specific methods } \\
\hline LEC & Lectin gene of soybean (Glycine max L.) & 81 & {$[74]$} \\
\hline$A D H$ & Alcohol dehydrogenase I gene from maize (Zea mays L.) & 83 & {$[73]$} \\
\hline$C R U$ & Cruciferin gene from oilseed rape (Brassica napus) & 85 & {$[73]$} \\
\hline$P L D$ & Phospholipase D gene from rice (Oryza sativa) & 80 & {$[73]$} \\
\hline$S A D 1$ & Stearoyl-acyl carrier protein desaturase gene of cotton (Gossypium genus) & 107 & {$[75]$} \\
\hline \multirow[t]{2}{*}{ GLU3 } & Glutamine synthetase gene from sugar beet (Beta vulgaris) & 118 & {$[31]$} \\
\hline & \multicolumn{3}{|l|}{ Generic element-specific methods } \\
\hline p35S & Promoter of the $35 \mathrm{~S}$ cauliflower mosaic virus & 75 & {$[28]$} \\
\hline tNOS & Terminator of the nopaline synthase gene & 69 & {$[28]$} \\
\hline pFMV & Promoter of the figworth mosaic virus & 79 & {$[76]$} \\
\hline pNOS & Promoter of the nopaline synthase gene & 75 & {$[76]$} \\
\hline \multirow[t]{2}{*}{$\mathrm{t} 35 \mathrm{~S}$} & Terminator of the cauliflower mosaic virus & 107 & in-house \\
\hline & \multicolumn{3}{|l|}{ GM element-specific methods } \\
\hline $\operatorname{cryIAb/Ac}$ & Gene encoding the Bacillus thuringiensis $\delta$-endotoxin (insect resistance) & 73 & {$[68]$} \\
\hline $\operatorname{cry} 3 \mathrm{Bb}$ & Gene encoding the Bacillus thuringiensis $\delta$-endotoxin (insect resistance) & 105 & in-house \\
\hline pat & Phosphinotricin- $N$-acetyltransferases gene from Streptomyces viridochromogenes & 109 & {$[68]$} \\
\hline bar & Phosphinotricin- $N$-acetyltransferases gene from Streptomyces hygroscopicus & 69 & {$[68]$} \\
\hline \multirow[t]{2}{*}{ epsps } & $\begin{array}{l}\text { 5-enolpyruvylshikimate-3-phosphate synthase gene from Agrobacterium tumefaciens } \\
\text { strain CP4 }\end{array}$ & 108 & {$[68]$} \\
\hline & \multicolumn{3}{|l|}{ p35S discriminating method } \\
\hline CRT & Reverse transcriptase gene from the cauliflower mosaic virus & 94 & in-house \\
\hline
\end{tabular}

mutation screening method with high potential for GMO analysis, including UGM analysis. HRM can be complemented with confirmation of the mutation by sequencing.

However, the screening methodology will no longer fully be suited for the detection of new types of genetic modifications that are under development through new plant breeding techniques. In the case of cisgenesis, for example, detection of the inserted elements alone can no longer be used as evidence of the genetic modification. However, the order of the different elements and the insertion loci into the plant genome still may offer an opportunity for the detection of these modifications [38]. Provided this information is available, these event-specific sequences can be exploited to develop new real-time PCR-based methods if needed. Also for other types of genetic modifications introduced by these new plant breeding techniques (e.g., ZFN technology, ODM) a minimum amount of information about the DNA sequence of the modification and the neighbouring sequence needs to be known to be able to detect them [60]. Without prior knowledge, detection of these small modifications would be unlikely to be used in routine laboratories as more complex technologies are needed (e.g., full-genome sequencing). For the others, the detection of the genetic modification is currently not possible (e.g., RdDM, grafting, reverse breeding, and agroinfiltration). In addition, crops resulting from most of the techniques cannot be distinguished from conventionally bred crops or from crops produced by natural genetic variation, and identification is therefore not possible [60].

These new advances in molecular biotechnology pose challenges to regulators as to whether they fall within the scope of their regulatory authority. In 2011, the European Commission, with the cooperation of different member states, published an overview of these techniques [60]. At the moment it is, however, not clear yet if these new breeding techniques lead to organisms that will be classified under the currently used GMO definition [85] and thus the GMO legislation. If they would be classified as GMO, they would require control and traceability. As the current methodologies will be insufficient, new approaches, probably involving a combination of different analytical methods, need to be developed. If they are not classified as GMO, the currently used detection methods would remain appropriate for now. Nevertheless, to anticipate the increasing number of GM events, the development of additional screening 


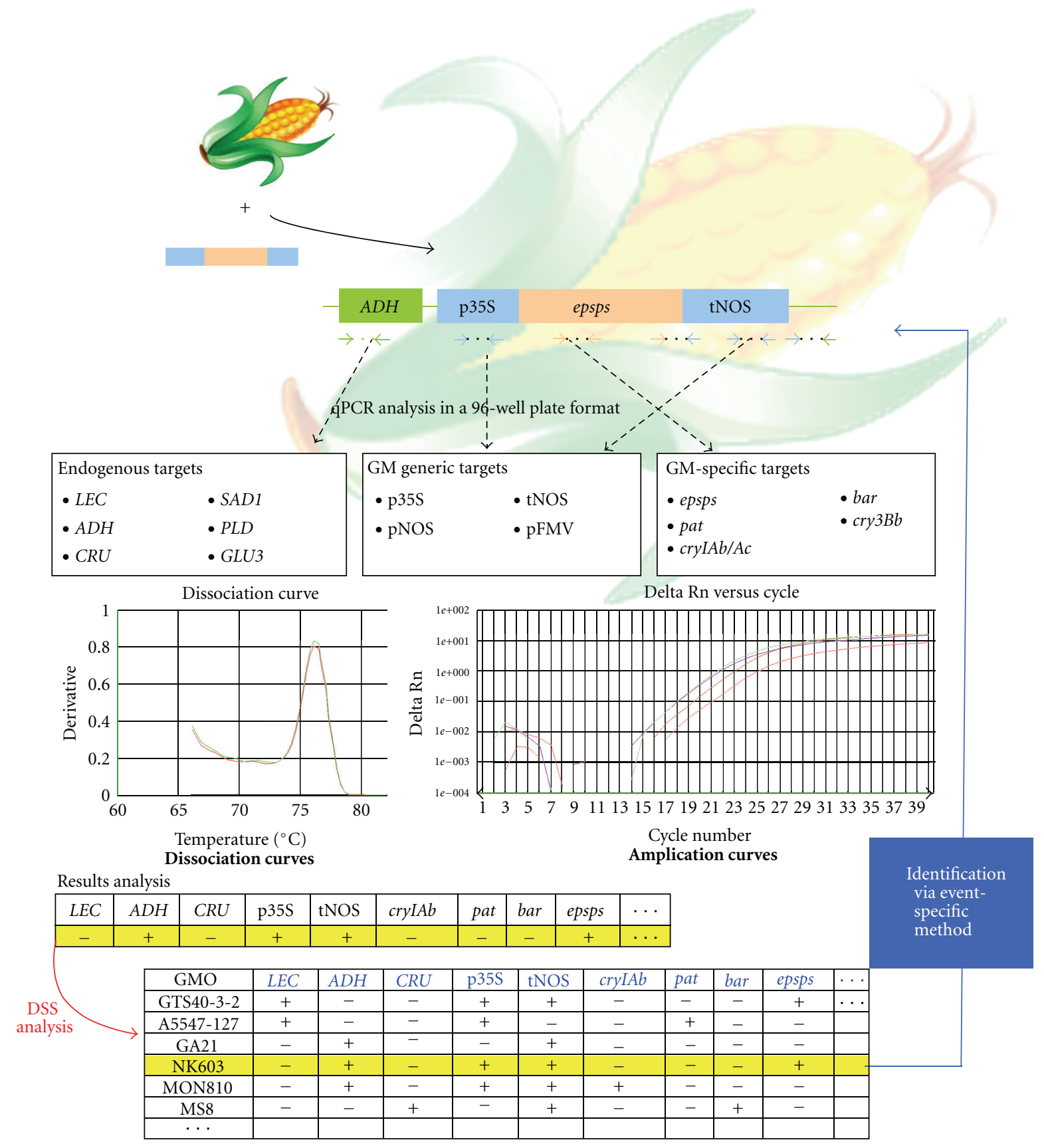

Figure 2: Example of the use of the CoSYPS for the detection of maize GM event NK603 (see text for details on the markers used). The following steps are performed. (1) Real-time PCR screening of the sample with the panel of markers. (2) Introduction of the results (Ct and $\mathrm{Tm}$ ) in the CoSYPS. (3) The CoSYPS gives a list of GM events possibly present in the sample. (4) Identification of the GM events using the event-specific methods.

markers, potentially in multiplex set-ups (which might involve technologies beyond the real-time PCR platforms), should be continued to arrive in the near future to a robust and cost-efficient solution to the GMO challenge.

\section{References}

[1] C. James, "Global status of commercialized biotech/GM crops: 2011. Executive summary,” ISAAA Brief 43, 2011.
[2] M. Dymond and K. Hurr, The Global Status of Commercialised Genetically Modified Plants (1 July 2008-31 December 2009), Plant Imports, MAF Biosecurity, Wellington, New Zealand, 2010.

[3] European Parliament, "Commission regulation (EC) No 1830/2003 of the European Parliament and of the Council of 22 September 2003 concerning the traceability and labelling of genetically modified organisms and the traceability of food and feed products produced from genetically modified 
organisms and amending Directive 2001/18/EC," Official Journal of the European Union, vol. L 268, pp. 24-28, 2003.

[4] C. E. Bean, "Japan Biotechnology MAFF's Biotech food labeling standards (revised)," GAIN Report JA2010, USDA, GAIN, 2002.

[5] G. W. Wiggin, "Russian federation. Food and agricultural import regulations and standards. New food safety and GMO labeling requirements," GAIN Report RS2020, USDA, 2002.

[6] A. J. Stein and E. Rodriguez-Cerezo, "The global pipeline of new GM crops. Implications of asynchroneous approval for international trade," EU23846-EN, 2009.

[7] L. de Suza, Brazilian Virus-Resistant Beans, BIOfortified, 2011.

[8] J. L. Fox, "Puzzling industry response to ProdiGene fiasco," Nature Biotechnology, vol. 21, no. 1, pp. 3-4, 2003.

[9] APHIS, Biotechnology. Noncompliance History, United States Department of Agriculture, Animal and Plant Health Inspection Service, USDA, 2011.

[10] M. L. Zapiola, C. K. Campbell, M. D. Butler, and C. A. Mallory-Smith, "Escape and establishment of transgenic glyphosate-resistant creeping bentgrass Agrostis stolonifera in Oregon, USA: a 4-year study," Journal of Applied Ecology, vol. 45, no. 2, pp. 486-494, 2008.

[11] P. Vermij, "Liberty Link rice raises specter of tightened regulations," Nature Biotechnology, vol. 24, no. 11, pp. 13011302, 2006.

[12] A. Holst-Jensen, "Testing for genetically modified organisms (GMOs): past, present and future perspectives," Biotechnology Advances, vol. 27, no. 6, pp. 1071-1082, 2009.

[13] D. Zhang and J. Guo, "The development and standardization of testing methods for genetically modified organisms and their derived products," Journal of Integrative Plant Biology, vol. 53, no. 7, pp. 539-551, 2011.

[14] W. Dong, L. Yang, K. Shen et al., "GMDD: a database of GMO detection methods," BMC Bioinformatics, vol. 9, article 260, 2008.

[15] M. Miraglia, K. G. Berdal, C. Brera et al., "Detection and traceability of genetically modified organisms in the food production chain," Food and Chemical Toxicology, vol. 42, no. 7, pp. 1157-1180, 2004.

[16] A. Holst-Jensen, M. De Loose, and G. Van Den Eede, "Coherence between legal requirements and approaches for detection of genetically modified organisms (GMOs) and their derived products," Journal of Agricultural and Food Chemistry, vol. 54, no. 8, pp. 2799-2809, 2006.

[17] E. Anklam, F. Gadani, P. Heinze, H. Pijnenburg, and G. D. Van Eede, "Analytical methods for detection and determination of genetically modified organisms in agricultural crops and plant-derived food products," European Food Research and Technology, vol. 214, no. 1, pp. 3-26, 2002.

[18] M. Querci, M. Van den Bulcke, J. Žel, G. Van Den Eede, and H. Broll, "New approaches in GMO detection," Analytical and Bioanalytical Chemistry, vol. 396, no. 6, pp. 1991-2002, 2010.

[19] A. K. Deisingh and N. Badrie, "Detection approaches for genetically modified organisms in foods," Food Research International, vol. 38, no. 6, pp. 639-649, 2005.

[20] N. Marmiroli, E. Maestri, M. Gullì et al., "Methods for detection of GMOs in food and feed," Analytical and Bioanalytical Chemistry, vol. 392, no. 3, pp. 369-384, 2008.

[21] J. Ovesna, K. Demnerova, and V. Pouchova, "GMO detection," in Food Microbiology and Food Safety, pp. 515-532, 2009.

[22] L. Grohmann, "Detection of genetically modified plants in seeds, food and feed," Biotechnology in Agriculture and Forestry, vol. 64, no. 1, pp. 117-136, 2010.
[23] Joint Research Centre, "Compendium of reference methods for GMO analysis," Tech. Rep. EUR 24526 EN, 2011.

[24] J. Mackay and O. Landt, "Real-time PCR fluorescent chemistries," in Protocols for Nucleic Acid Analysis by Nonradioactive Probes, E. Hilario and J. Mackay, Eds., Methods in Molecular Biology, pp. 237-261, Humana Press, Totwa, NJ, USA, 2nd edition, 2007.

[25] M. B. Gašparič, K. Cankar, J. Žel, and K. Gruden, "Comparison of different real-time PCR chemistries and their suitability for detection and quantification of genetically modified organisms," BMC Biotechnology, vol. 8, article 26, 2008.

[26] M. B. Gašparič, T. Tengs, J. L. La Paz et al., "Comparison of nine different real-time PCR chemistries for qualitative and quantitative applications in GMO detection," Analytical and Bioanalytical Chemistry, vol. 396, no. 6, pp. 2023-2029, 2010.

[27] Life Technologies, "TaqMan and SYBR Green Chemistries," http://www.appliedbiosystems.com/absite/us/en/home/applications-technologies/real-time-pcr/taqman-and-sybr-greenchemistries.html.

[28] E. Barbau-Piednoir, A. Lievens, G. Mbongolo-Mbella et al., "SYBR Green qPCR screening methods for the presence of "35S promoter" and "NOS terminator" elements in food and feed products," European Food Research and Technology, vol. 230, no. 3, pp. 383-393, 2010.

[29] L. Jiang, L. Yang, J. Rao et al., "Development and in-house validation of the event-specific qualitative and quantitative PCR detection methods for genetically modified cotton MON15985," Journal of the Science of Food and Agriculture, vol. 90, no. 3, pp. 402-408, 2010.

[30] S. Baeumler, D. Wulff, L. Tagliani, and P. Song, "A realtime quantitative PCR detection method specific to widestrike transgenic cotton (Event 281-24-236/3006-210-23)," Journal of Agricultural and Food Chemistry, vol. 54, no. 18, pp. 65276534, 2006.

[31] European Union Reference Laboratory for GM Food and Feed and Feed, "Event-specific method for the quantification of sugar beet line H7-1 using Real-time PCR: protocol," Tech. Rep. CRLVL28/04VP, 2006.

[32] H. H. Dörries, I. Remus, A. Grönewald, C. Grönewald, and K. Berghof-Jäger, "Development of a qualitative, multiplex realtime PCR kit for screening of genetically modified organisms (GMOs)," Analytical and Bioanalytical Chemistry, vol. 396, no. 6, pp. 2043-2054, 2010.

[33] I. J. Lu, C. H. Lin, and T. M. Pan, "Establishment of a system based on universal multiplex-PCR for screening genetically modified crops," Analytical and Bioanalytical Chemistry, vol. 396, no. 6, pp. 2055-2064, 2010.

[34] C. Bahrdt, A. B. Krech, A. Wurz, and D. Wulff, "Validation of a newly developed hexaplex real-time PCR assay for screening for presence of GMOs in food, feed and seed," Analytical and Bioanalytical Chemistry, vol. 396, no. 6, pp. 2103-2112, 2010.

[35] J. Guo, L. Yang, L. Chen et al., "MPIC: a high-throughput analytical method for multiple DNA targets," Analytical Chemistry, vol. 83, no. 5, pp. 1579-1586, 2011.

[36] S. Hamels, T. Glouden, K. Gillard et al., "A PCR-microarray method for the screening of genetically modified organisms," European Food Research and Technology, vol. 228, no. 4, pp. 531-541, 2009.

[37] A. Nadal, T. Esteve, and M. Pla, "Multiplex polymerase chain reaction-capillary gel electrophoresis: a promising tool for gmo screening-assay for simultaneous detection of five genetically modified cotton events and species," Journal of AOAC International, vol. 92, no. 3, pp. 765-772, 2009. 
[38] A. Holst-Jensen, Y. Bertheau, M. de Loose et al., "Detecting un-authorized genetically modified organisms (GMOs) and derived materials," Biotechnology Advances. In press.

[39] J. T. Odell, F. Nagy, and N. H. Chua, "Identification of DNA sequences required for activity of the cauliflower mosaic virus 35S promoter," Nature, vol. 313, no. 6005, pp. 810-812, 1985.

[40] A. Depicker, S. Stachel, and P. Dhaese, "Nopaline synthase: transcript mapping and DNA sequence," Journal of Molecular and Applied Genetics, vol. 1, no. 6, pp. 561-573, 1982.

[41] A. Wehrmann, A. Van Vliet, C. Opsomer, J. Botterman, and A. Schulz, "The similarities of bar and pat gene products make them equally applicable for plant engineers," Nature Biotechnology, vol. 14, no. 10, pp. 1274-1278, 1996.

[42] G. Kishore, D. Shah, S. Padgette et al., "5-enolpyruvylshikimate 3-phosphate synthase," in Biochemistry to Genetic Engineering of Glyphosate Tolerance, American Chemical Society, P. A. Hedin, J. J. Menn, and R. M. Hollingworth, Eds., pp. 37-48, 1988.

[43] S. R. Padgette, D. B. Re, G. F. Barry et al., "New weed control opportunities: development of soybeans with a Roundup Ready gene," in Herbicide-Resistant Crops: Agricultural, Environmental, Economic, Regulatory, and Technical Aspects, pp. 53-84, 1996.

[44] Agbios, http://www.cera-gmc.org/?action=gm_crop_data-base $\&$.

[45] GMO Compass, http://www.gmo-compass.org/eng/home/.

[46] M. Sanger, S. Daubert, and R. M. Goodman, "Characteristics of a strong promoter from figwort mosaic virus: comparison with the analogous $35 \mathrm{~S}$ promoter from cauliflower mosaic virus and the regulated mannopine synthase promoter," Plant Molecular Biology, vol. 14, no. 3, pp. 433-443, 1990.

[47] D. McElroy, W. Zhang, J. Cao, and R. Wu, "Isolation of an efficient actin promoter for use in rice transformation," The Plant Cell, vol. 2, no. 2, pp. 163-171, 1990.

[48] A. H. Christensen, R. A. Sharrock, and P. H. Quail, "Maize polyubiquitin genes: structure, thermal perturbation of expression and transcript splicing, and promoter activity following transfer to protoplasts by electroporation," Plant Molecular Biology, vol. 18, no. 4, pp. 675-689, 1992.

[49] D. Gonsalves, "Transgenic papaya in Hawaii and beyond," AgBioForum, vol. 7, no. 1-2, pp. 36-40, 2004.

[50] W. Cai, C. Gonsalves, P. Tennant et al., "A protocol for efficient transformation and regeneration of Carica papaya L.," In Vitro Cellular and Developmental Biology, vol. 35, no. 1, pp. 61-69, 1999.

[51] P. F. Tennant, M. H. Ahmad, and D. Gonsalves, "Transformation of Carica papaya L. with virus coat protein genes for studies on resistance to Papaya ringspot virus from Jamaica," Tropical Agriculture, vol. 79, no. 2, pp. 105-113, 2002.

[52] N. Acciarri, G. Vitelli, S. Arpaia, G. Mennella, F. Sunseri, and G. L. Rotino, "Transgenic resistance to the Colorado potato beetle in Bt-expressing eggplant fields," HortScience, vol. 35, no. 4, pp. 722-725, 2000.

[53] H. J. J. Koehorst-van Putten, E. Sudarmonowati, M. Herman et al., "Field testing and exploitation of genetically modified cassava with low-amylose or amylose-free starch in Indonesia," Transgenic Research, vol. 21, no. 1, pp. 39-50, 2012.

[54] K. Sriroth, K. Piyachomkwan, V. Santisopasri, and C. G. Oates, "Environmental conditions during root development: drought constraint on cassava starch quality," Euphytica, vol. 120, no. 1, pp. 95-101, 2001.

[55] I. Taverniers, N. Papazova, Y. Bertheau, M. De Loose, and A. Holst-Jensen, "Gene stacking in transgenic plants: towards compliance between definitions, terminology, and detection within the EU regulatory framework," Environmental Biosafety Research, vol. 7, no. 4, pp. 197-218, 2008.

[56] OECD, OECD Guidance for the Designation of a Unique Identifier for transgenic plants, vol. 23, 2002.

[57] X. Ye, S. Al-Babili, A. Klöti et al., "Engineering the provitamin A ( $\beta$-carotene) biosynthetic pathway into (carotenoid-free) rice endosperm," Science, vol. 287, no. 5451, pp. 303-305, 2000.

[58] P. Beyer, "Golden Rice and "Golden" crops for human nutrition,” New Biotechnology, vol. 27, no. 5, pp. 478-481, 2010.

[59] Dow AgroSciences, http://www.dowagro.com/.

[60] M. Lusser, C. Parisi, D. Plan et al., "New plant breedings techniques. State-of-the-art and prospects for commercial development," European Commisson EUR 24760 EN, 2011.

[61] European Union Reference Laboratory for GM Food and Feed (EU-RL GMFF): Status of dossier web-page, http://gmo-crl.jrc.ec.europa.eu/ .

[62] S. Bruderer, K. E. Leitner, and J. Lindenmeyer, Genetically Modified (GM) Crops: Molecular and Regulatory Details, BATS, Centre for Biosafety and Sustainability, 2003.

[63] H. U. Waiblinger, B. Ernst, A. Anderson, and K. Pietsch, "Validation and collaborative study of a P35S and T-nos duplex real-time PCR screening method to detect genetically modified organisms in food products," European Food Research and Technology, vol. 226, no. 5, pp. 1221-1228, 2008.

[64] S. Fernandez, C. Charles-Delobel, A. Geldreich et al., "Quantification of the $35 \mathrm{~S}$ promoter in DNA extracts from genetically modified organisms using real-time polymerase chain reaction and specificity assessment on various genetically modified organisms, part I: operating procedure," Journal of AOAC International, vol. 88, no. 2, pp. 547-557, 2005.

[65] M. Höhne, C. R. Santisi, and R. Meyer, "Real-time multiplex PCR: an accurate method for the detection and quantification of 35S-CaMV promoter in genetically modified maizecontaining food," European Food Research and Technology, vol. 215, no. 1, pp. 59-64, 2002.

[66] P. Corbisier, S. Trapmann, D. Gancberg et al., "Quantitative determination of Roundup Ready soybean (Glycine max) extracted from highly processed flour," Analytical and Bioanalytical Chemistry, vol. 383, no. 2, pp. 282-290, 2005.

[67] R. Reiting, H. Broll, H. U. Waiblinger, and L. Grohmann, "Collaborative study of a T-nos real-time PCR method for screening of genetically modified organisms in food products," Journal für Verbraucherschutz und Lebensmittelsicherheit, vol. 2, no. 2, pp. 116-121, 2007.

[68] E. Barbau-Piednoir, A. Lievens, E. Vandermassen et al., "Four new SYBR Green qPCR screening methods for the detection of Roundup Ready, LibertyLink, and CryIAb traits in genetically modified products," European Food Research and Technology, vol. 234, no. 1, pp. 13-23, 2012.

[69] L. Grohmann, C. B. Nieweler, A. Nemeth, and H. U. Waiblinger, "Collaborative trial validation studies of real-time PCRbased GMO Screening methods for detection of the bar gene and the ctp2-cp4epsps construct," Journal of Agricultural and Food Chemistry, vol. 57, no. 19, pp. 8913-8920, 2009.

[70] A. Z. Dinon, T. W. Prins, J. P. Van Dijk, A. C. M. Arisi, I. M. J. Scholtens, and E. J. Kok, "Development and validation of realtime PCR screening methods for detection of cry1A.105 and cry $2 A b 2$ genes in genetically modified organisms," Analytical and Bioanalytical Chemistry, vol. 400, no. 5, pp. 1433-1442, 2011.

[71] M. Van den Bulcke, A. Lievens, E. Barbau-Piednoir et al., "A theoretical introduction to "combinatory SYBR Green qPCR Screening", a matrix-based approach for the detection of 
materials derived from genetically modified plants," Analytical and Bioanalytical Chemistry, vol. 396, no. 6, pp. 2113-2123, 2010.

[72] S. Broeders, N. Papazova, M. Van den Bulcke et al., "Development of a molecular platform for GMO detection in food and feed on the basis of, "combinatory qPCR" technology," in Polymerase Chain Reaction, P. Hernández-Rodríguez and A. P. R. Gome, Eds., vol. 1, pp. 363-404, InTech, Rijeka, Croatia, 2012.

[73] E. G. Mbongolo Mbella, A. Lievens, E. Barbau-Piednoir et al., "SYBR Green qPCR methods for detection of endogenous reference genes in commodity crops: a step ahead in combinatory screening of genetically modified crops in food and feed products," European Food Research and Technology, vol. 232, no. 3, pp. 485-496, 2011.

[74] M. Vaïtilingom, H. Pijnenburg, F. Gendre, and P. Brignon, "Real-time quantitative PCR detection of genetically modified maximizer maize and roundup ready soybean in some representative foods," Journal of Agricultural and Food Chemistry, vol. 47, no. 12, pp. 5261-5266, 1999.

[75] L. Yang, J. Chen, C. Huang et al., "Validation of a cottonspecific gene, Sad1, used as an endogenous reference gene in qualitative and real-time quantitative PCR detection of transgenic cottons," The Plant Cell Reports, vol. 24, no. 4, pp. 237-245, 2005.

[76] S. Broeders, E. Barbau-Piednoir, E. Vandermassen, F. Debode, M. Mazzara, and N. Roosens, "New SYBRGreen methods targeting promoter sequences used for screening of several GM events pending for authorisation in Europe," submitted.

[77] European Parliament, "Regulation (EC) No 1829/2003 of the European Parliament and of the Council of 22 September 2003 on genetically modified food and feed," Official Journal of the European Union, vol. L 268, pp. 1-23, 2003.

[78] European Commission, "Commission Regulation (EU) No 619/2011 of 24 June 2011 laying down the methods of sampling and analysis for the official control of feed as regards presence of genetically modified material for which an authorisation procedure is pending or the authorisation of which has expired," Official Journal of the European Union, vol. L166, pp. 9-15, 2011.

[79] T. Ruttink, R. Demeyer, E. Van Gulck et al., "Molecular toolbox for the identification of unknown genetically modified organisms," Analytical and Bioanalytical Chemistry, vol. 396, no. 6, pp. 2073-2089, 2010.

[80] V. Thirulogachandar, P. Pandey, C. S. Vaishnavi, and M. K. Reddy, "An affinity-based genome walking method to find transgene integration loci in transgenic genome," Analytical Biochemistry, vol. 416, no. 2, pp. 196-201, 2011.

[81] GAO, "Genetically engineered crops. Agencies are proposing changes to improve oversight, but could take additional steps to enhance coordination and monitoring," Report GAO-0960, United States Government Accountability Office, 2008.

[82] H. Akiyama, T. Watanabe, K. Wakabayashi et al., "Quantitative detection system for maize sample containing combined-trait genetically modified maize," Analytical Chemistry, vol. 77, no. 22, pp. 7421-7428, 2005.

[83] R. H. A. M. Vossen, E. Aten, A. Roos, and J. T. Den Dunnen, "High-resolution melting analysis (HRMA)—-more than just sequence variant screening," Human Mutation, vol. 30, no. 6, pp. 860-866, 2009.

[84] A. L. F. Gady, F. W. K. Hermans, M. H. B. J. Van de Wal, E. N. van Loo, R. G. F. Visser, and C. W. B. Bachem, "Implementation of two high through-put techniques in a novel application: detecting point mutations in large EMS mutated plant populations," Plant Methods, vol. 5, no. 1, article 13, 2009.

[85] "Directive 2001/18/EC of the European Parliament and of the Council of 12 March 2001 on the deliberate release into the environment of genetically modified organisms and repealing Council Directive 90/220/EEC," Official Journal of the European Union, vol. L 106, pp. 1-38, 2001. 

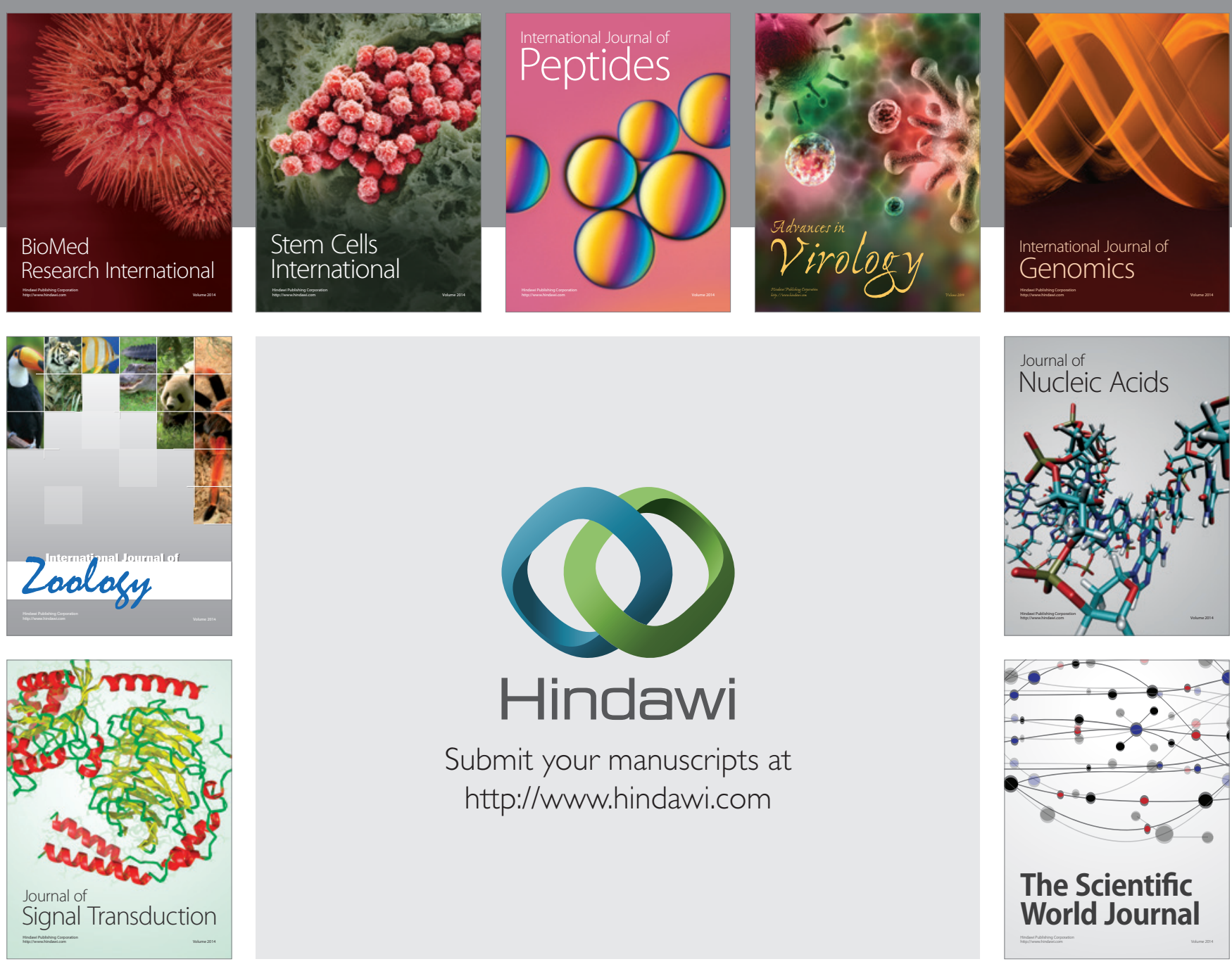

Submit your manuscripts at

http://www.hindawi.com
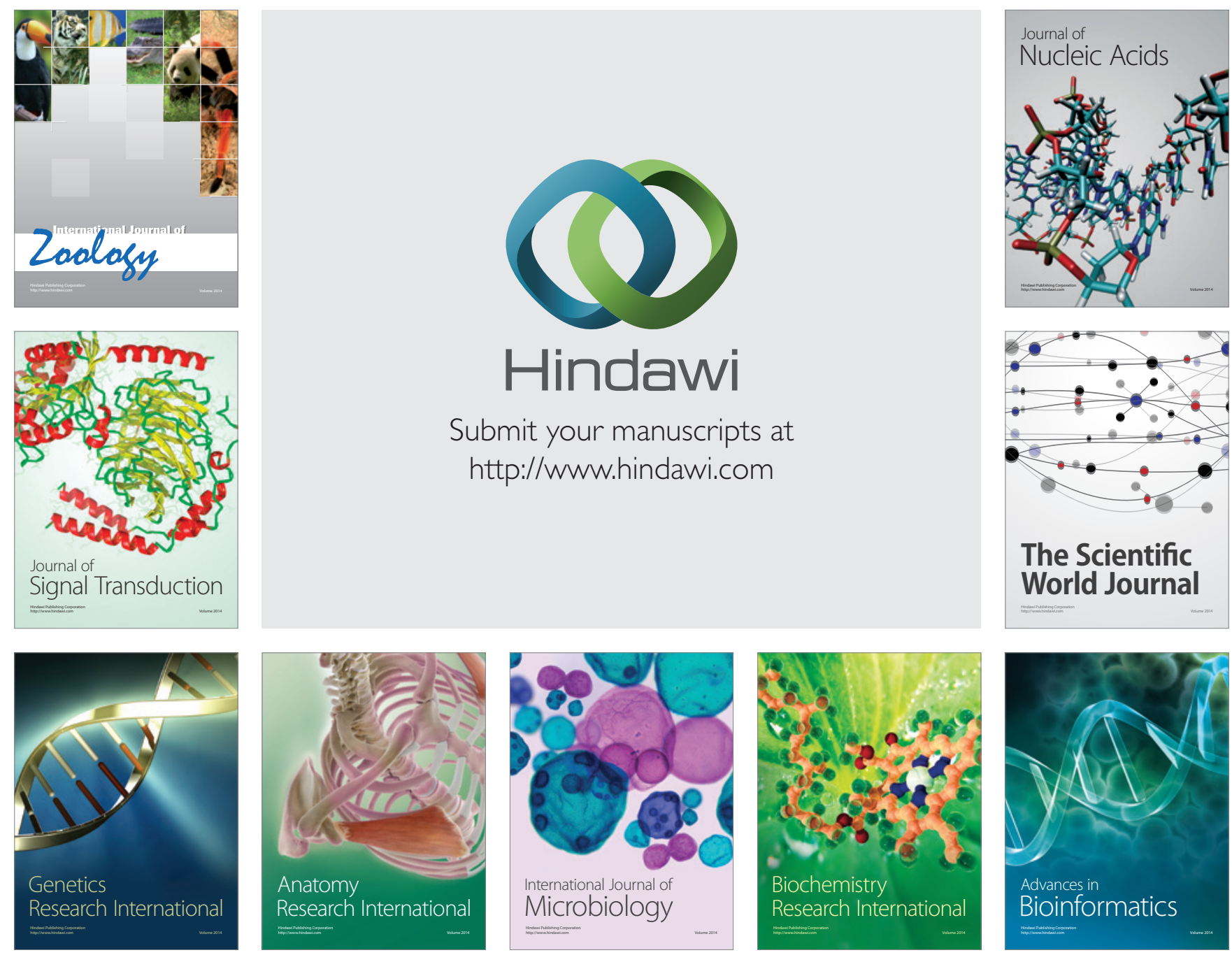

The Scientific World Journal
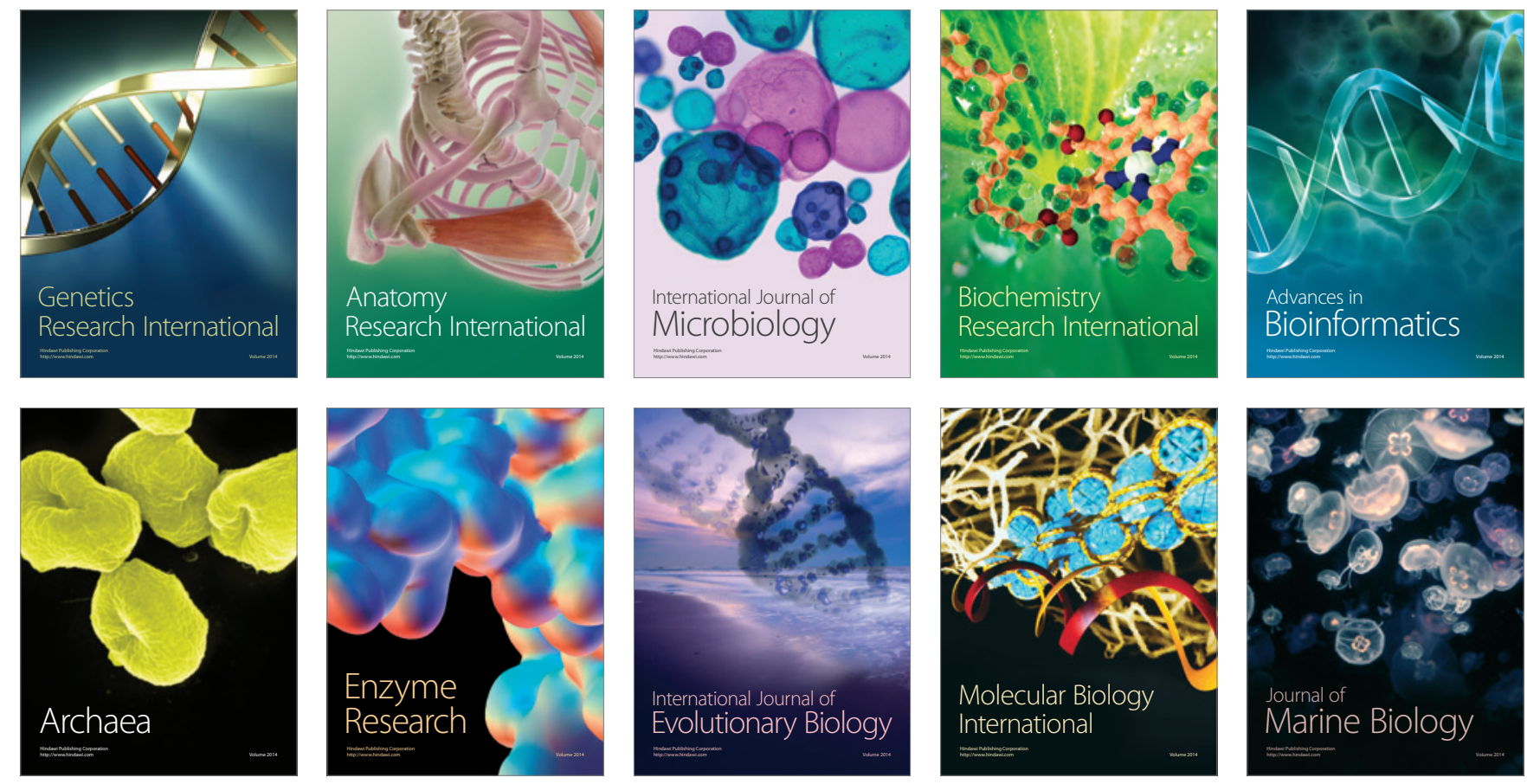